\title{
Angiotensin Type 1A Receptors in C1 Neurons of the Rostral Ventrolateral Medulla Modulate the Pressor Response to Aversive Stress
}

\author{
Daian Chen, ${ }^{1}$ Nikola Jancovski, ${ }^{1}$ Jaspreet K. Bassi, ${ }_{1}^{1}$ Thu-Phuc Nguyen-Huu, ${ }^{3}$ Yan-Ting Choong, ${ }^{1}$ Kesia Palma-Rigo, ${ }^{3}$ \\ Pamela J. Davern, ${ }^{3}$ Susan B. Gurley, ${ }^{4}$ Walter G. Thomas, ${ }^{5}$ Geoffrey A. Head, ${ }^{3 \star}$ and Andrew M. Allen ${ }^{1,2 \star}$ \\ ${ }^{1}$ Department of Physiology and ${ }^{2}$ Florey Neurosciences Institutes, University of Melbourne, Melbourne, Victoria 3010, Australia, ${ }^{3}$ Neuropharmacology \\ Laboratory, Baker IDI Heart and Diabetes Institute, Melbourne, Victoria 3004, Australia, ${ }^{4}$ Division of Nephrology, Department of Medicine, Duke \\ University and Durham VA Medical Centers, Durham, North Carolina 27710, and ${ }^{5}$ School of Biomedical Sciences, University of Queensland, St. Lucia, \\ Queensland 4072, Australia
}

The rise in blood pressure during an acute aversive stress has been suggested to involve activation of angiotensin type $1 \mathrm{~A}$ receptors $\left(\mathrm{AT}_{1 \mathrm{~A}} \mathrm{Rs}\right)$ at various sites within the brain, including the rostral ventrolateral medulla. In this study we examine the involvement of $\mathrm{AT}_{1 \mathrm{~A}} \mathrm{Rs}$ associated with a subclass of sympathetic premotor neurons of the rostral ventrolateral medulla, the $\mathrm{C} 1$ neurons. The distribution of putative $\mathrm{AT}_{1 \mathrm{~A}} \mathrm{R}$-expressing cells was mapped throughout the brains of three transgenic mice with a bacterial artificial chromosomeexpressing green fluorescent protein under the control of the $\mathrm{AT}_{1 \mathrm{~A}} \mathrm{R}$ promoter. The overall distribution correlated with that of the $\mathrm{AT}_{1 \mathrm{~A}} \mathrm{Rs}_{\mathrm{S}}$ mapped by other methods and demonstrated that the majority of $\mathrm{C} 1$ neurons express the $\mathrm{AT}_{1 \mathrm{~A}} \mathrm{R}$. Cre-recombinase expression in $\mathrm{C} 1$ neurons of $\mathrm{AT}_{1 \mathrm{~A}} \mathrm{R}$-floxed mice enabled demonstration that the pressor response to microinjection of angiotensin II into the rostral ventrolateral medulla is dependent upon expression of the $\mathrm{AT}_{1 \mathrm{~A}} \mathrm{R}$ in these neurons. Lentiviral-induced expression of wild-type $\mathrm{AT}_{1 \mathrm{~A}} \mathrm{Rs}_{\text {in }}$ $\mathrm{C} 1$ neurons of global $\mathrm{AT}_{1 \mathrm{~A}} \mathrm{R}$ knock-out mice, implanted with radiotelemeter devices for recording blood pressure, modulated the pressor response to aversive stress. During prolonged cage-switch stress, expression of $\mathrm{AT}_{1 \mathrm{~A}} \mathrm{Rs}$ in $\mathrm{C} 1$ neurons induced a greater sustained pressor response when compared to the control viral-injected group ( $22 \pm 4 \mathrm{mmHg}_{\text {for }} \mathrm{AT}_{1 \mathrm{~A}} \mathrm{R}$ vs $10 \pm 1 \mathrm{mmHg}$ for GFP; $p<0.001$ ), which was restored toward that of the wild-type group $(28 \pm 2 \mathrm{mmHg})$. This study demonstrates that $\mathrm{AT}_{1 \mathrm{~A}} \mathrm{R}$ expression by $\mathrm{C} 1$ neurons is essential for the pressor response to angiotensin II and that this pathway plays an important role in the pressor response to aversive stress.

\section{Introduction}

The response to stress involves coordinated activation of the autonomic nervous system and the hypothalamic-pituitary-adrenal axis (Ulrich-Lai and Herman, 2009). While stress responses are essential physiology, there is a growing recognition that aberrant, or sustained, stress exposure is detrimental and can lead to the development of hypertension (Esler, 2009).

Both systemic and brain angiotensin systems play important roles in the responses to stress (Saavedra and Benicky, 2007). Treatment of hypertensive patients with an angiotensin converting enzyme inhibitor lowers blood pressure (BP) and reduces the

Received Oct. 24, 2011; revised Dec. 12, 2011; accepted Dec. 21, 2011.

Author contributions: D.C., N.J., J.K.B., Y.-T.C., W.G.T., G.A.H., and A.M.A. designed research; D.C., N.J., J.K.B., T.-P.N.-H., Y.-T.C., K.P.-R., and A.M.A. performed research; S.B.G. contributed unpublished reagents/analytic tools; D.C., N.J., T.-P.N.-H., Y.-T.C., K.P.-R., P.J.D., S.B.G., W.G.T., G.A.H., and A.M.A. analyzed data; D.C., N.J., W.G.T., G.A.H., and A.M.A. wrote the paper.

This work was supported by National Heart Foundation of Australia Grant G07M3186, Australian Research Council Grant DP1094301, and National Health and Medical Research Council of Australia Grants 566563 and 1007451.

*G.A.H. and A.M.A. are joint senior authors for this publication

The authors declare no competing financial interests.

Correspondence should be addressed to Dr. Andrew M. Allen, Department of Physiology, University of Melbourne, Melbourne, VIC 3010, Australia. E-mail: a.allen@unimelb.edu.au.

DOI:10.1523/JNEUROSCI.5360-11.2012

Copyright $\odot 2012$ the authors $\quad 0270-6474 / 12 / 322051-11 \$ 15.00 / 0$ pressor response to mental stress (Kahan and Eliasson, 1999). Experimental animal studies have demonstrated a role for brain angiotensin II (AngII), acting through its type $1 \mathrm{~A}$ receptor $\left(\mathrm{AT}_{1 \mathrm{~A}} \mathrm{R}\right)$, in the neuroendocrine and autonomic response to stress. This is particularly clear for corticotrophin-releasing hormone release induced by $\mathrm{AT}_{1 \mathrm{~A}} \mathrm{R}$ stimulation in the hypothalamus (Aguilera et al., 1995; $\mathrm{Ar}-$ mando et al., 2001). Studies in mice also implicate the $\mathrm{AT}_{1 \mathrm{~A}} \mathrm{R}$ in the pressor response to aversive stress, as global genetic deletion of the $\mathrm{AT}_{1 \mathrm{~A}} \mathrm{R}$ leads to an attenuated pressor response to aversive stress, but not to appetitive stimuli (Chen et al., 2009).

The rostral ventrolateral medulla (RVLM) is a critical site for regulation of sympathetic vasomotor activity (Dampney, 1994) and is proposed to be involved in the cardiovascular response to aversive stress, although this involvement remains controversial (Vianna and Carrive, 2010). Studies conducted in conscious rabbits showed that the stress-induced pressor response consists of at least two components acting in the RVLM-an initial response, mediated by glutamate, followed by a sustained response (Mayorov and Head, 2002, 2003). Local microinjections of $\mathrm{AT}_{1} \mathrm{R}$ antagonists in the RVLM attenuate the sustained pressor response (Mayorov and Head, 2003). These observations indicate that the RVLM may be an important node connecting the effects of AngII on stimulation of the autonomic nervous system in aversive stress. 
The RVLM contains moderate to high densities of $\mathrm{AT}_{1} \mathrm{Rs}$ in most species, including humans (Allen et al., 1998). The RVLM contains at least two major subtypes of presympathetic neurons based on their expression of catecholamine synthetic enzymes. One group, the $\mathrm{C} 1$ neurons, expresses all of the enzymes required to synthesize adrenaline (Phillips et al., 2001), whereas the other group expresses none of these enzymes and is referred to as non-C1 neurons (Lipski et al., 1995; Schreihofer and Guyenet, 1997). The relative involvement of these different cell groups in the pressor response to aversive stress remains unclear. Recently, it was shown that $\mathrm{C} 1$ neurons of the RVLM have the capacity to induce a sympathetically mediated increase in $\mathrm{BP}$ (Abbott et al., 2009) and that expression of the $\mathrm{AT}_{1 \mathrm{~A}} \mathrm{R}$ in $\mathrm{C} 1$ neurons of $\mathrm{AT}_{1 \mathrm{~A}} \mathrm{R}$ knock-out $\left(A T_{1 A} R^{--}\right)$mice reinstates the sympathoexcitation induced by AngII in the RVLM (Chen et al., 2010). Therefore, the aim of this current study is to examine the effect of transgenic expression of the $\mathrm{AT}_{1 \mathrm{~A}} \mathrm{R}$ in the $\mathrm{C} 1$ neurons of the RVLM on the cardiovascular responses to acute aversive stress in conscious $A T_{1 A} R^{-/-}$mice.

\section{Materials and Methods}

Experiments followed the Australian National Health and Medical Research Council Code of Practice for the Care and Use of Animals for Scientific Purposes and were approved by the University of Melbourne and the Alfred Medical Research Education Precinct Animal Ethics Committees. $A T_{1 A} R^{-/-}$mice and their own control strain $\left(A T_{1 A} R^{+/+}\right)$ were bred in the animal facilities at the Baker IDI Heart and Diabetes Research Institute (Melbourne, VIC, Australia). Mice were originally obtained from Prof. T. Walther (Charité, Berlin, Germany), who produced $\mathrm{F} 2$ generation crosses of $(129 \times \mathrm{C} 57 \mathrm{BL} / 6 \mathrm{~J}) \mathrm{F} 1 A T_{1 \mathrm{~A}} R^{-/+}$parents maintained on a C57Bl/6 background (Gembardt et al., 2008). Mice with a conditional Agtrla allele $\left(A T_{1 A} R^{f l f l}\right)$ were generated using standard gene targeting methods (Gurley et al., 2011) and obtained from Dr. S. Gurley and Prof. T. Coffman (Duke University, Durham, NC). They were maintained as a homozygote line on a C57BL/6 background at the Florey Neurosciences Institute (University of Melbourne, Melbourne, VIC, Australia). Cre-recombinase (Cre) reporter mice (ROSA26-eYFP, where eYFP is enhanced yellow fluorescent protein) were obtained from Prof. F. Costantini, Columbia University, New York, NY (Srinivas et al., 2001) and maintained at the Florey Neurosciences Institute, University of Melbourne. All mice were genotyped using standard PCR protocols. All mice were maintained under $12 \mathrm{~h}$ light/dark cycle (lights on from 6 A.M. to 6 P.M.) with ad libitum access to standard chow and water. Brains from three male adult mice, in which enhanced green fluorescent protein (GFP) and a polyadenylation signal were inserted before the ATG start codon of the Agtrla gene ( $\left.p A T_{1 A} R-G F P\right)$, were obtained from the GenSat BAC transgenic project (GENSAT). These had been deeply anesthetized, perfused with $4 \%$ paraformaldehyde, and stored in $20 \%$ sucrose solution for shipping from the United States to Australia. The brains were frozen in isopentane on dry ice and stored at $-80^{\circ} \mathrm{C}$ before histological processing of serial sections taken every $300 \mu \mathrm{m}$ throughout the entire neuraxis.

\section{Lentiviral injection in RVLM}

Replication-deficient lentiviruses with transgene expression under the control of a synthetic phox2-selective promoter (PRSx8) were injected bilaterally into the RVLM of anesthetized mice $(80 \mathrm{mg} / \mathrm{kg}$ ketamine, 10 $\mathrm{mg} / \mathrm{kg}$ xylazine, i.p.) (Chen et al., 2010). Before surgery mice, were injected with a nonsteroidal analgesic (Carprofen, $5 \mathrm{mg} / \mathrm{ml}, 0.5 \mathrm{mg} / 100 \mathrm{~g}$, i.p; Norbrook Laboratories) and anesthesia induced by inhalation of isoflurane (Rhodia Australia) in a sealed container. Three different viruses were used that induced expression of GFP (Lv-PRSx8-GFP; titer, $2 \times 10^{11}$ viral particles per milliliter), wild-type hemagglutinin-tagged $\mathrm{AT}_{1 \mathrm{~A}} \mathrm{R}$ (Lv-PRSx8-AT ${ }_{1 \mathrm{~A}} \mathrm{R}$; titer, $3.7 \times 10^{11}$ viral particles per milliliter), or Cre (Lv-PRSx8-Cre; titer, $3.9 \times 10^{10}$ viral particles per milliliter). A detailed description of the methods used to generate and characterize these viruses, including the demonstration that injection of Lv-PRSx8-
$\mathrm{AT}_{1 \mathrm{~A}} \mathrm{R}$-induced expression of $\mathrm{AT}_{1 \mathrm{~A}} \mathrm{Rs}$ capable of altering neuronal activity upon stimulation, has been published previously (Chen et al., 2010). Anesthetized mice were placed in a stereotaxic apparatus (Benchmark stereotaxic instruments; MyNeurolab) in a prone position. The position of the head was adjusted so that the skull surface was horizontal. A midline incision was made over the occipital bone, and portions of the bone overlying the cerebellum were carefully removed with a dental drill while keeping the lambdoid suture intact. The lambdoid and midline sutures served as reference points for rostrocaudal and lateral coordinates, respectively. Microinjections (100 $\mathrm{nl}$ per site) were made to the RVLM, $1.2 \mathrm{~mm}$ lateral to the midline and $5.3 \mathrm{~mm}$ ventral to the dorsal surface of the brain at three rostrocaudal coordinates, 1.7, 1.9, and 2.1 $\mathrm{mm}$ caudal to lambda. Microinjections were made through pulled glass micropipettes (1B100F-4; World Precision Instruments), with tip diameters of $30-50 \mu \mathrm{m}$. Solutions were ejected using pressurized nitrogen gas delivered via a pneumatic pressure device (SYS-PV820; World Precision Instruments), and volumes were determined by observation of movement of the fluid meniscus using a monocular microscope fitted with an eye-piece graticule (Cole-Parmer). Upon completion of the injection, the incision was closed with surgical silk stitches. Mice received atipamezole hydrochloride ( $1 \mathrm{mg} / \mathrm{kg}$, i.p.; Antisedan; VMS Supplies) to reverse the anesthesia. Each mouse was housed individually. ROSA26-eYFP mice were injected unilaterally with Lv-PRSx8-Cre. $A T_{1 A} R^{f l f l}$ mice were injected bilaterally with either Lv-PRSx8-Cre or Lv-PRSx8-GFP. $A T_{1 A} R^{-/-}$mice were injected bilaterally with either Lv-PRSx8-AT ${ }_{1 \mathrm{~A}} \mathrm{R}$ or Lv-PRSx8-GFP and used in long-term studies to assess cardiovascular control and stress responses.

\section{Verification of viral-induced Cre expression}

Approximately 4 weeks after microinjection of Lv-PRSx8-Cre into the RVLM, the ROSA26-eYFP mice $(n=3)$ were deeply anesthetized using the anesthetic protocol described above and perfused with $4 \%$ paraformaldehyde, and the brains removed for histological processing.

\section{RVLM microinjections in anesthetized mice}

Approximately 4 weeks after bilateral microinjection of Lv-PRSx8-Cre $(n=6)$ or Lv-PRSx8-GFP $(n=6)$ into the RVLM, $A T_{1 A} R^{f l / f l}$ mice were anesthetized by inhalation of isoflurane $(1.8-2 \%)$ to study the acute cardiovascular response to microinjection of glutamate and AngII into the RVLM. Standard protocols were used as described previously (Chen et al., 2010). Briefly, mice were maintained at a rectal temperature of $37^{\circ} \mathrm{C}$ using a servocontrolled heating blanket, tracheotomized, and artificially ventilated (UGO Basile mouse ventilator 28025) with oxygen. End-tidal $\mathrm{CO}_{2}$ was measured (CWE) and maintained between 2.5 and $3.5 \%$. The left carotid artery was cannulated for measurement of BP (Neurolog System; Digitimer), and heart rate (HR) was derived from the digitized signal (Cambridge Electronic Design). Fluid balance was maintained by subcutaneous injection of Hartmann's solution (Baxter Healthcare). Mice were placed in a stereotaxic frame, as described for injections above, and either glutamate $(10 \mathrm{nl}$ of a $10 \mathrm{~mm}$ solution) or AngII (50 $\mathrm{nl}$ of a $1 \mathrm{~mm}$ solution; AusPep) were microinjected into the RVLM. Several injections of glutamate were made to identify the site that produced an immediate rise in arterial pressure. Injections were made independently into both sides of the brain, with a period of at least $30 \mathrm{~min}$ elapsing between AngII microinjections. The AngII solution contained a $1 \%$ concentration of rhodamine-labeled microspheres (Invitrogen) to enable histological identification of the injection site postmortem. At the completion of the experiment, mice were deeply anesthetized and perfused with $4 \%$ paraformaldehyde, and the brains removed for histological analysis of GFP or CD68 expression, to localize viral injection sites, and rhodamine-labeled microspheres.

\section{Cardiovascular and stress responses in RVLM Lv-PRSx8-AT} $R$-injected knock-out mice

Telemetry implantation. Under isoflurane anesthesia (Abbott Laboratories), $A T_{1 A} R^{-/-}(n=12)$ and $A T_{1 A} R^{+/+}(n=6)$ mice were implanted with PA-C10 telemeters (Data Sciences International) in the left carotid artery as described previously (Butz and Davisson, 2001). Both before surgery and on the first day following surgery, each mouse received pain relief (Carprofen, $0.5 \mathrm{mg} / 100$ g, i.p.; Norbrook). Each mouse received 0.5 
$\mathrm{ml}$ saline subcutaneously at the time of operation and then again $24 \mathrm{~h}$ after operation. Mice were kept warm on a heat pad and monitored until fully recovered from anesthesia. Each mouse was housed individually, and the mouse cages were half kept on a heated surface for $24-48 \mathrm{~h}$ to assist in their thermoregulation. Two weeks after telemetry implantation, baseline $24 \mathrm{~h}$ recordings of $\mathrm{BP}$ were made, and on the next day, bilateral injections of either Lv-PRSx8-AT ${ }_{1 \mathrm{~A}} \mathrm{R}(n=7)$ or Lv-PRSx8-GFP $(n=5)$ were made into the RVLM of $A T_{1 A} R^{-/-}$mice.

Cardiovascular measurements. Pulsatile arterial pressure was recorded continuously, sampled at $1 \mathrm{kHz}$ using an analog-to-digital data acquisition card (PCI-8024E; National Instruments), and the beat-to-beat mean arterial pressure (MAP) and HR were detected on-line and analyzed using a program written in Labview (Head et al., 2001; Navakatikyan et al., 2002). An index of locomotor activity was obtained by monitoring changes in the received signal strength, which occurred upon movement of the animal. For detection of activity, the mouse had to move location. Therefore, with the transmitter implanted subcutaneously, slight movements during grooming or eating were not registered as activity. Systolic, mean, and diastolic BP, pulse interval, and locomotor activity were stored in text format on an IBM-compatible computer. Baseline cardiovascular parameters were observed for an additional 4 weeks with recordings over a consecutive $24 \mathrm{~h}$ period every week.

Autonomic activity was assessed by monitoring spontaneous changes in BP and HR. Beat-to-beat MAP and HR were analyzed between 10 A.M. and 1 P.M. (during the inactive period) on 2 consecutive days. The autopower and cross-power spectra were calculated for multiple overlapping (by $50 \%$ ) segments of MAP and HR using fast Fourier transform (Head et al., 2001). The average value used as the estimate of the baroreflex sensitivity in this study is the mid-frequency band $(0.3-0.5 \mathrm{~Hz})$ and relates to autonomic function (Janssen and Smits, 2002). Other frequency bands analyzed were the low-frequency band $(0.08-0.3 \mathrm{~Hz})$ and the high-frequency band $(0.5-3 \mathrm{~Hz})$. Normalized power was obtained by dividing the cumulative power within each frequency band by the total power (Head et al., 2004; Baudrie et al., 2007).

Stress test protocols. Blood pressure, HR, and locomotor activity were recorded continuously throughout the experiment. Restraint and feeding tests were performed on the same day but separated by at least $60 \mathrm{~min}$ of recovery period (or until BP returned to baseline levels) with a quiet rest period of at least $5 \mathrm{~min}$ before the commencement of each test. To test the reproducibility of stress responses, all tests were repeated, in random order, on the following day. As there was no difference in cardiovascular responses to stress on Experimental Days 1 and 2, the data were pooled and treated as repeated measures for subsequent analysis. The cage-switch test was conducted approximately 1 week later on the final day of experimental protocol. All mice were then perfused for immunohistochemistry.

Feeding test. A piece of almond $(\sim 0.5 \mathrm{~g})$, a novel palatable stimulus, was placed in the home cage. This is accompanied by marked increases in BP and HR (Jackson et al., 2007; Chen et al., 2009). The mouse was observed from when it commenced eating until when it ceased eating. The average change in MAP and HR over the first 5 min was used to estimate the magnitude of cardiovascular response to feeding (De Matteo et al., 2006).

Restraint stress. Mice were placed in a cylindrical Plexiglas container used for tail cuff BP measurements (length, $135 \mathrm{~mm}$; diameter, $50 \mathrm{~mm}$; Harvard Apparatus). The sliding plate was moved to confine the mouse without applying physical pressure to it. The restrained mouse was left in the restrainer in its home cage for $5 \mathrm{~min}$ before being released.

Cage-switch stress. All mice were placed in a clean cage and maintained in that cage without further cleaning for at $7 \mathrm{~d}$ before cage-switch stress. This is a model of acute psychosocial stress (Lee et al., 2004). During the light period on the day of the study, $1 \mathrm{~h}$ of baseline recording was made with the mice undisturbed in their home cage. The mice were then placed into a cage occupied previously (for $7 \mathrm{~d}$ ) by a different male mouse for a period of $1 \mathrm{~h}$. The pressor response is reproducible, takes over $90 \mathrm{~min}$ after beginning cage-switch test to subside, and is accompanied by significant increases in HR and motor activity in mice (Lee et al., 2004). The cage-switch test was conducted approximately 1 week after the restraint and feed tests on the final day of the experimental protocol. All mice were then anesthetized and perfused for immunohistochemistry processing.
Data analysis. Cardiovascular responses to microinjection of glutamate and AngII into the RVLM of viral-injected $A T_{1 A} R^{f l f l}$ mice were measured as the $10 \mathrm{~s}$ average maximal response after microinjection of either glutamate or AngII and compared to a $60 \mathrm{~s}$ preinjection control period. For analysis of the responses to restraint and novel almond feeding stimuli, $30 \mathrm{~s}$ averages of MAP, HR, and activity signals were determined for the period $5 \mathrm{~min}$ before the stimulus, $5 \mathrm{~min}$ during the stimulus, and $5 \mathrm{~min}$ after the stimulus. For analysis of the responses to dirty-cage-switch stress, 10 min averages of MAP, HR, and activity signals were determined for the period $1 \mathrm{~h}$ before the cage switch and $1 \mathrm{~h}$ during the cage switch.

Statistical analysis. All variables are presented as mean \pm SEM. Changes in arterial pressure and heart rate in response to glutamate and AngII microinjection into the RVLM were compared by two-way repeated-measures ANOVA followed by a pairwise multiple comparison (Holm-Sidak method; SigmaPlot version 11; Systat Software). Cardiovascular data from the telemetered mice were analyzed by a split-plot repeated-measures ANOVA where the between-group sums of squares due to change over time or stress were used to compare the differences between Lv-PRSx8-GFP- and Lv-PRSx8-AT ${ }_{1 \mathrm{~A}} \mathrm{R}$-injected $A T_{1 A} R^{-1-}$ mice and control, uninjected $A T_{1 A} R^{+/+}$mice. For the $24 \mathrm{~h}$ recordings over $33 \mathrm{~d}$ before and after microinjection, individual between-group Bonferroni-adjusted contrasts were made to compare values at Days 0, 7, 13, 20,27, and 33. The degrees of freedom of the ANOVA were adjusted by the Greenhouse-Geisser coefficient to reduce the interdependence of repeated variables. Values were considered significant at $p<0.05$.

Histological processing. At the completion of each experimental proto$\mathrm{col}$, anesthesia was induced in all mice by inhalation of isoflurane and then injection of ketamine/xylazine as described above. They were perfused through the heart with saline $(0.9 \% \mathrm{NaCl})$ followed by a solution of $4 \%$ formaldehyde in $0.1 \mathrm{~mol} / \mathrm{L}$ sodium phosphate buffer. The brains were removed, postfixed in formaldehyde for $1-2 \mathrm{~h}$, and then cryoprotected in $20 \%$ sucrose overnight at $4^{\circ} \mathrm{C}$. Brainstem sections were cut on a cryostat (Microm International) and serial coronal $40 \mu \mathrm{m}$ sections were collected in four series and stored in cryoprotectant [30\% (w/v) sucrose, $30 \%(\mathrm{v} / \mathrm{v})$ ethylene glycol, $1 \%(\mathrm{w} / \mathrm{v})$ polyvinyl-pyrrolidone in $50 \mathrm{~mm}$ phosphate buffer, $\mathrm{pH}$ 7.2] until immunohistochemical staining as described previously (Llewellyn-Smith et al., 2003; Chen et al., 2010). Brains from $p A T_{1 A} R-G F P$, Lv-PRSx8-GFP-injected $A T_{1 A} R^{-/-}$and $A T_{1 A} R^{f l f l}$ and Lv-PRSx8-Cre-injected ROSA26-eYFP mice were processed for immunohistochemical double staining of tyrosine hydroxylase (TH) and GFP. The Lv-PRSx8-AT ${ }_{1 \mathrm{~A}} \mathrm{R}$-injected $A T_{1 A} R^{-/-}$mice and LvPRSx8-Cre-injected $A T_{1 A} R^{f l / f l}$ mice were processed for TH and the macrophage marker $\mathrm{CD} 68$, which is a reliable marker for the injection site (Card et al., 2006). The primary antibodies were rat anti-mouse CD68 (1:1000; AbD Serotec), rabbit anti-TH (1:500; Millipore Bioscience Research Reagents), and chicken anti-GFP (1:1000; Millipore Bioscience Research Reagents). The secondary antibodies were Alexa Fluor 488-conjugated goat anti-chicken (1: 200), Cy3-conjugated donkey anti-rabbit (1:200), Dylight 549 goat anti-rat (1: 200; AbD Serotec), or Alexa Fluor 488 goat anti-rabbit (1:200; Vector Laboratories), as required. Immunofluorescence was imaged using an Axio Imager D.1 microscope connected to an AxioCam MRc5 digital camera (both from Zeiss) and mapping performed with reference to the mouse brain atlas (Paxinos and Franklin, 2004).

\section{Results}

\section{Distribution of $\mathrm{AT}_{1 \mathrm{~A}} \mathrm{R}$-expressing neurons in the mouse} brain

The distribution of neurons expressing GFP in the $p A T_{1 A} R-G F P$ mouse was examined throughout the brain in serial sections, taken every $300 \mu \mathrm{m}$, in three mice. The distribution of GFPexpressing cells was consistent between all the mice examined. Green fluorescent protein labeling was found in the soma and processes of cells with neuronal morphology, and no labeling was obvious in cells that were morphologically similar to astrocytes or glia. The distribution of GFP immunoreactivity throughout the brain was consistent with previous studies examining $\mathrm{AT}_{1} \mathrm{R}$ distribution in the mouse brain (Jenkins et al., 1997) with no evidence of 


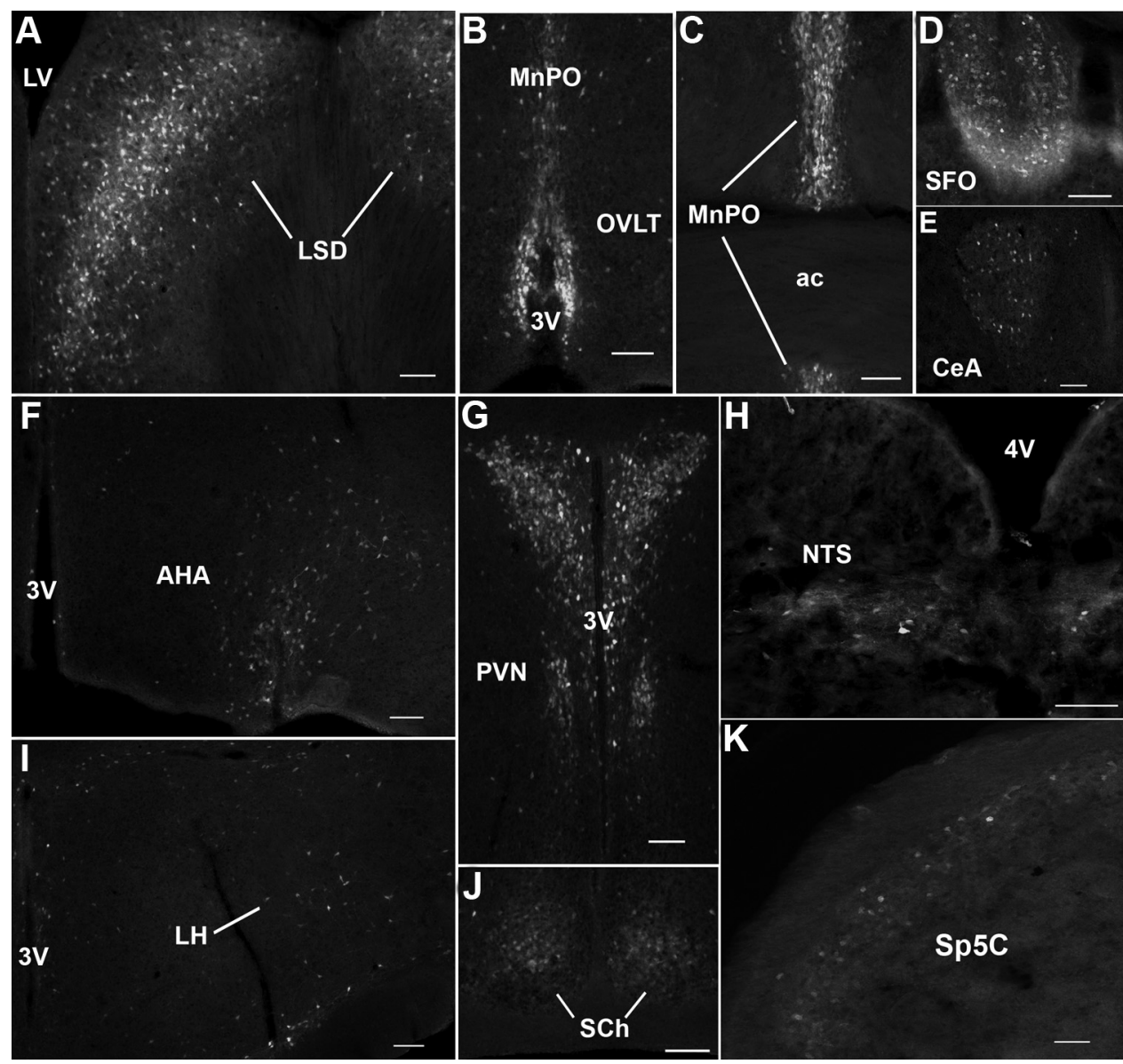

Figure 1. $\boldsymbol{A}-\boldsymbol{K}$, Photomicrographs of coronal sections at different levels of the neuraxis showing GFP immunoreactivity in $p A T_{1 A} R$-GFP transgenic mice. The white cell profiles show GFP expression. Scale bars: $100 \mu \mathrm{m}$. ac, Anterior commissure; AHA, anterior hypothalamic area; cc, central canal; CeA, central nucleus of the amygdala; LH, lateral hypothalamus; LSD, dorsal subnucleus of the lateral septal nucleus; LV, lateral ventricle; MnP0, median preoptic nucleus; NTS, nucleus of the solitary tract; OVLT, organum vasculosum of the lamina terminalis; PVN, hypothalamic paraventricular nucleus; $\mathrm{SCh}$, suprachiasmatic nucleus; SF0, subfornical organ; Sp5C, caudal part of the spinal trigeminal nucleus; $3 \mathrm{~V}$, third ventricle; $4 \mathrm{~V}$, fourth ventricle.

ectopic expression. Some regions, such as the area postrema, were expected to display GFP immunoreactivity but did not. The cerebellum and spinal cord were not examined in this study.

\section{Forebrain}

A dense population of GFP-labeled neurons occurred in the dorsal lateral septal nucleus (Fig. $1 A$ ), vascular organ of the lamina terminalis (Fig. $1 B$ ), median preoptic nucleus (Fig. $1 B, C$ ), and subfornical organ (Fig. $1 D$ ). Numerous GFP-expressing neurons were observed in the parvocellular subdivisions of the hypothalamic paraventricular nucleus (Fig. $1 G$ ), the periventricular hypothalamic nucleus (Fig. $1 G$ ), and the suprachiasmatic nucleus (Fig. $1 \mathrm{H}$ ). Within the hypothalamic paraventricular nucleus, no colocalization was observed between GFP and TH, indicating that the $\mathrm{AT}_{1 \mathrm{~A}} \mathrm{R}$-expressing cells were not part of the A12 dopaminergic cell group (data not shown). Scattered GFP-labeled cells occurred in the anterior hypothalamic area (Fig. $1 E$ ), lateral hypothalamic area (Fig. $1 F$ ), dorsal medial hypothalamic area (data not shown), and arcuate nucleus. Scattered neurons in the caudate-putamen (data not shown) and central nucleus of the amygdala (Fig. 1I) also showed GFP labeling. No GFP labeling was observed in the hippocampus, thalamic nuclei, supraoptic nucleus, or magnocellular component of paraventricular hypothalamic nucleus.

Midbrain and pons

A distinct cluster of GFP-positive cells occurred in the dorsomedial interpeduncular nucleus of the pons (Fig. $1 B$ ), and scattered GFPpositive cells were seen in the lateral superior olive (data not shown).

\section{Medulla}

Neurons expressing GFP were observed in the dorsal medulla in the nucleus of the solitary tract (Fig. $1 \mathrm{~J}$ ) and the dorsal motor nucleus of the vagus (data not shown). In addition, GFP-positive terminals were prominent within the nucleus of the solitary tract. Surprisingly, no GFP labeling was observed in area postrema. The nucleus ambiguus contained a compact group of GFP-expressing cells (data not shown). GFP-labeled neurons were also present throughout the caudal nucleus of the spinal trigeminal tract (Fig. $1 \mathrm{~K}$ ). Within the RVLM (Fig. $2 \mathrm{~A}$ ), caudal ventrolateral medulla (data not shown), and nucleus of the solitary tract (data not shown), the majority of GFP-positive cells also expressed TH immunoreactivity (Fig. $2 \mathrm{~B}$ ) and thus represent the $\mathrm{C} 1, \mathrm{~A} 1$, and A2 cell groups, respectively. A small proportion ( 10\%) of GFPlabeled cells that were non-TH-immunoreactive were observed in both the RVLM (Fig. 2A) and caudal ventrolateral medulla.

Lentiviral-induced Cre expression and conditional knock-out Microinjection of Lv-PRSx8-Cre into the RVLM of

ROSA26-eYFP mice

To verify the cell selectivity and level of Cre-recombinase expression when delivered as a lentiviral transgene, Lv-PRSx8-Cre was microinjected into the RVLM of ROSA26-eYFP mice. Approximately 4 weeks after injection, robust eYFP expression was observed within the RVLM, which predominantly ( 90\%) colocalized with TH immunoreactivity (Fig. 2D-F). 

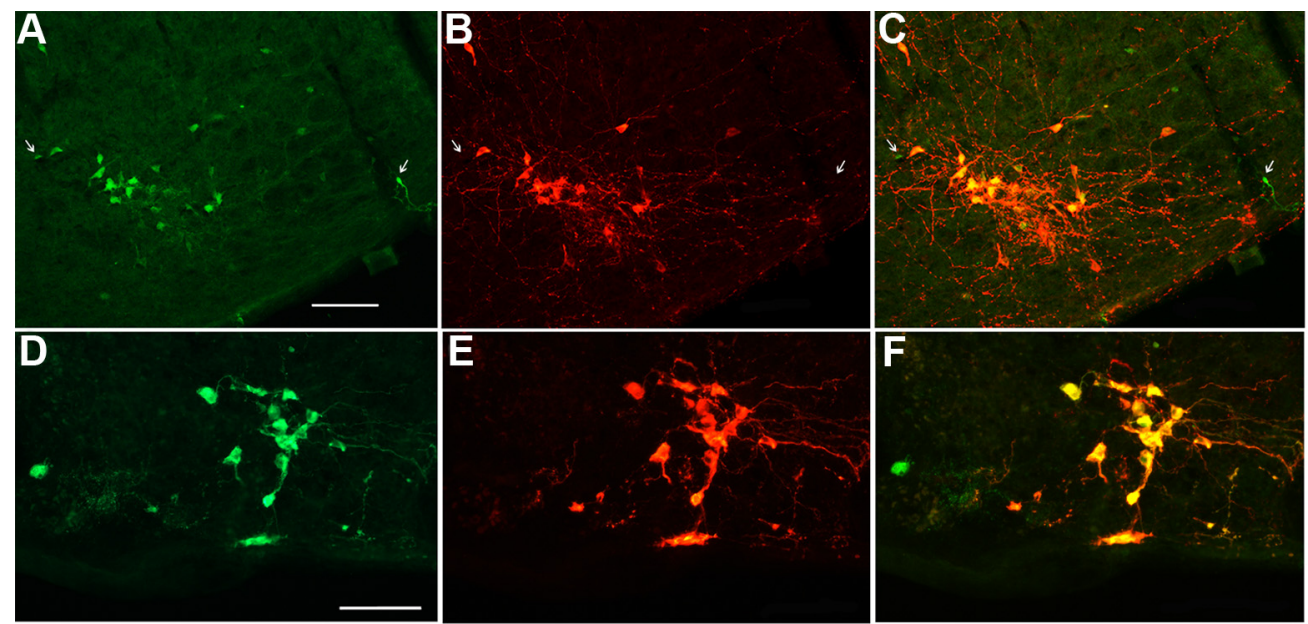

G

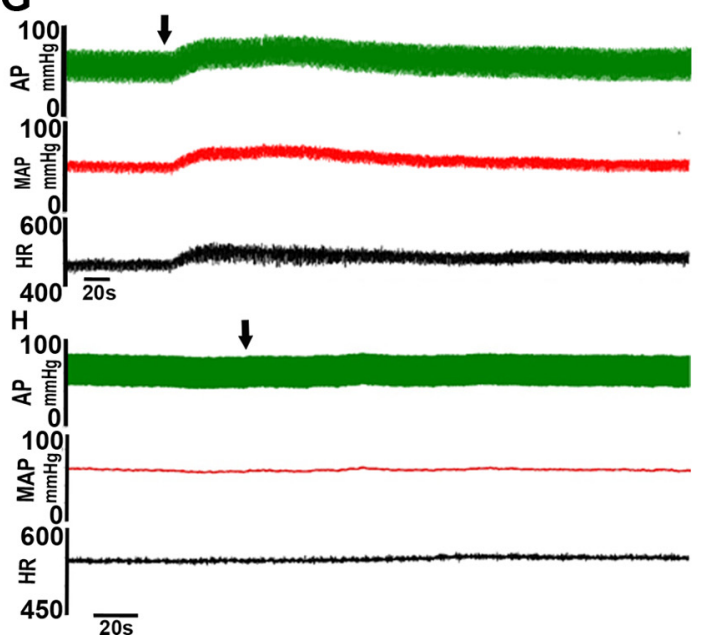

I

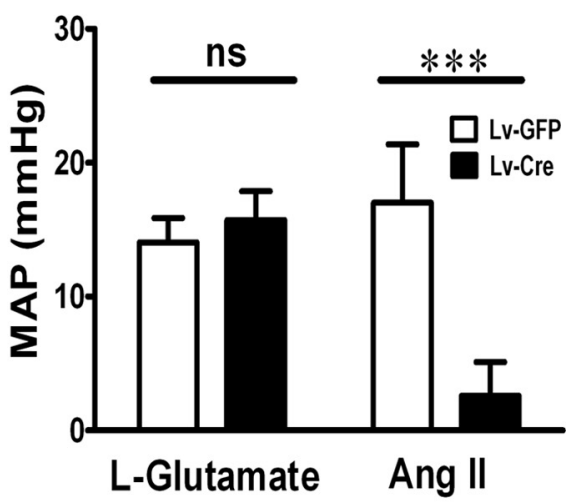

Figure 2. $\quad \boldsymbol{A}-\boldsymbol{F}$, Photomicrographs of fluorescence immunohistochemistry images showing $\operatorname{GFP}(\boldsymbol{A}, \boldsymbol{D}), \operatorname{TH}(\boldsymbol{B}, \boldsymbol{E})$, and the merged images $(\boldsymbol{C}, \boldsymbol{F})$ at the level of the RVLM from a $p A T_{1 A} R-G F P$ mouse $(\boldsymbol{A}-\boldsymbol{C})$ and a ROSA26-eYFP mouse injected with Lv-PRSx8-Cre virus $(\boldsymbol{D}-\boldsymbol{F})$. Within the RVLM of a pAT $1 A$ R-GFP mouse the majority of GFP-expressing neurons also expresses TH. The arrows point to the few neurons that are clearly GFP positive that do not express TH. Following microinjection of Lv-PRSX8-GFP into the RVLM of a ROSA26-eYFP mouse, the majority of YFP expression occurs in TH-expressing cells. $\mathbf{G}, \boldsymbol{H}$, Arterial pressure (AP; in millimeters mercury), MAP (in millimeters mercury), and HR (bpm) were recorded in anesthetized $A T_{1 A} R^{f / f t}$ mice injected $\sim 4$ weeks earlier with Lv-PRsx8-GFP $(\boldsymbol{G})$ or Lv-PRSx8-Cre $(\boldsymbol{H})$ into the RVLM. Microinjection of Angll into the RVLM (arrows) induced an increase in MAP and HR in the Lv-PRsx8-GFP-injected animals that was similar to that observed previously in wild-type mice. This response was markedly attenuated in Lv-PRSx8-Cre injected mice.I, The grouped data ( $n=6$ for each group) showing the response to microinjection of glutamate and Angll into the RVLM of these animals. Scale bars: 100 . ns, No significant difference between groups. ${ }^{* * *} p<0.001$.

\section{Response to RVLM microinjection of angiotensin II following} cell-selective $A T_{1 A} R$ deletion

Four weeks after bilateral microinjection of Lv-PRSx8-Cre or Lv-PRSx8-GFP into the RVLM of $A T_{1 A} R^{f l / f l}$ mice, there was no difference in baseline BP or HR under isoflurane (1.8-2.0\%) anesthesia [GFP vs Cre: MAP, $86 \pm 8 \mathrm{mmHg}$ and $76 \pm 5 \mathrm{mmHg}$; $\mathrm{HR}, 538 \pm 30$ beats per minute $(\mathrm{bpm})$ and $518 \pm 16 \mathrm{bpm}$; not significant]. Microinjection of $10 \mathrm{~mm}$ glutamate $(10 \mathrm{nl})$ resulted in a robust and rapid increase in BP (Fig. 2I) when localized within the RVLM. Comparison of maximal responses revealed no difference between Lv-PRSx8-Cre- and Lv-PRSx8GFP-injected animals. Microinjection of $1 \mathrm{~mm}$ AngII $(50 \mathrm{nl})$ similarly resulted in a robust increase in BP, although with a longer time to reach maximum than glutamate, in the Lv-PRSx8GFP-injected animals (Fig. $2 G$ ). In contrast, the response to AngII was dramatically attenuated in Lv-PRSx8-Cre-injected $A T_{1 A} R^{f l f l}$ mice (not significant compared to baseline) (Fig. $2 \mathrm{H}$ ). Postmortem analysis revealed that all microinjections included in this study were within $50-400 \mu \mathrm{m}$ of the caudal pole of the facial nucleus and correlated with the distribution of $\mathrm{TH}$ - immunoreactive neurons.

\section{Behavioral experiments}

Verification of lentiviral injection sites

At the completion of the cage-switch stress tests, the mice were killed, and their brains were removed for histology. Verification of lentiviral-induced GFP expression was performed postmortem by immunohistochemistry with colocalization with TH (Fig. $3 A-C)$. The site of Lv-PRSx8-AT ${ }_{1 \mathrm{~A}} \mathrm{R}$ injections was visualized by examination of CD68 expression and colocalized with TH immunohistochemistry (Fig. 3D-F). For all mice included in this study, the microinjections were within the region of $\mathrm{TH}$-expressing neurons and within $500 \mu \mathrm{m}$ of the caudal pole of the facial motor nucleus. Schematic coronal sections of mouse medulla oblongata modified from the atlas of Paxinos and Franklin (2004), showing the range of all viral microinjections in mice from this study, are included (Fig. 3G). Previous studies using identical protocols have quantified expression of the $\mathrm{AT}_{1} \mathrm{R}$ binding site density in RVLM following lentiviral injections in $A T_{1 A} R^{-/-}$mice (Chen et al., 2010). Those studies indicated that transgene expression resulted in an increase of $97 \% \mathrm{AT}_{1 \mathrm{~A}} \mathrm{R}$ expression above the level of endogenous receptor expression in the RVLM of a wild-type 
mouse. This remains less than the level of endogenous $\mathrm{AT}_{1} \mathrm{R}$ expression in other brain regions such as the nucleus of the solitary tract.

Average body weights of Lv-PRSx8GFP- and Lv-PRSx8-AT ${ }_{1 A}$ R-injected $A T_{1 A} R^{-/-}$mice were not different throughout the experiment (Week 0,23.2 $\pm 1.0 \mathrm{~g}$ vs $23.3 \pm 0.6$ g; Week $5,24 \pm 1.2 \mathrm{~g}$ vs $24.0 \pm$ $0.7 \mathrm{~g}$, respectively). The $A T_{1 A} R^{+/+}$mice weighed $30 \pm 0.5 \mathrm{~g}$.

\section{Basal cardiovascular measurements}

The $24 \mathrm{~h}$ average basal MAP and HR were similar between both groups of $A T_{1 A} R^{-/-}$ mice at Week 0 , before RVLM microinjection of Lv-PRSx8-GFP or Lv-PRSx8-AT ${ }_{1 \mathrm{~A}} \mathrm{R}$ (Fig. 4). Seven days after viral microinjections, Lv-PRSx8-GFP mice had a transient increase in MAP and HR compared to LvPRSx8-AT ${ }_{1 \mathrm{~A}} \mathrm{R}$ mice $(100 \pm 1 \mathrm{mmHg}$ vs $83 \pm 1 \mathrm{mmHg}, p<0.001 ; 585 \pm 6 \mathrm{bpm}$ vs $489 \pm 5$ bpm, $p<0.001)$. At all other times there was no difference in $24 \mathrm{~h}$ average MAP, HR, or locomotor activity between groups (Fig. 4).

A distinct circadian pattern of MAP, $\mathrm{HR}$, locomotor activity, and time spent active was observed in both groups, characterized by higher values of these parameters during the night (Fig. 5). Analysis of the circadian variation of BP showed that at Weeks 3-5 the Lv-PRSx8-AT ${ }_{1 \mathrm{~A}} \mathrm{R}$ injected mice had a small decrease in MAP during the inactive, light period $(-6.6 \pm$ $3.3 \mathrm{mmHg} ; p<0.05)$, with no change in the dark period $(-2.8 \pm 3.4 \mathrm{mmHg}$ ) (Fig. $5 B)$. There was no change in any of the other measured parameters. At the time of the stress responses, the $A T_{1 A} R^{+/+}$mice had a significantly higher resting blood pressure and heart rate compared to the Lv injected $A T_{1 A} R^{-/-}$mice (MAP, $A T_{1 A} R^{+/+}, 108 \pm 0.2 \mathrm{mmHg}$; Lv-PRSx8GFP, $77 \pm 1 \mathrm{mmHg}$; Lv-PRSx8-AT ${ }_{1 \mathrm{~A}} \mathrm{R}$, $74 \pm 1 \mathrm{mmHg}$; HR: $A T_{1 A} R^{+/+}, 508 \pm 7$ bpm; Lv-PRSx8-GFP, $435 \pm 10$ bpm; LvPRSx8-AT ${ }_{1 \mathrm{~A}} \mathrm{R}, 411 \pm 11 \mathrm{bpm}$ ).

Autonomic activity was assessed indirectly by monitoring spontaneous changes in BP and HR using power spectral analysis. The average power of MAP and HR variability in all frequency spectral bands was similar in all mice before RVLM microinjections of Lv-PRSx8-AT ${ }_{1 \mathrm{~A}} \mathrm{R}$ or Lv-PRSx8-GFP during the light period (inactive period) (Table 1 ). The average power of $\mathrm{HR}$ variability in the low-, mid-, and high-frequency bands during the inactive period was similar between $\mathrm{Lv}-\mathrm{PRS} \mathrm{x} 8-\mathrm{AT}_{1 \mathrm{~A}} \mathrm{R}$ and Lv-PRSx8-GFP RVLM-microinjected mice (Table 1). However, the total power of HR variability (the average across low, middle, and high frequencies) was smaller in the Lv-PRSx8-AT ${ }_{1 \mathrm{~A}} \mathrm{R}$ - compared to Lv-PRSx8-GFP-microinjected mice at Day $33\left(926 \pm 126 \mathrm{bpm}^{2}\right.$ vs $1538 \pm 158 \mathrm{bpm}^{2} ; p<0.05$ ) (Table 1 ). The spontaneous baroreflex sensitivity (midfrequency of the HR variability spectra) was similar before and after viral microinjections, as well
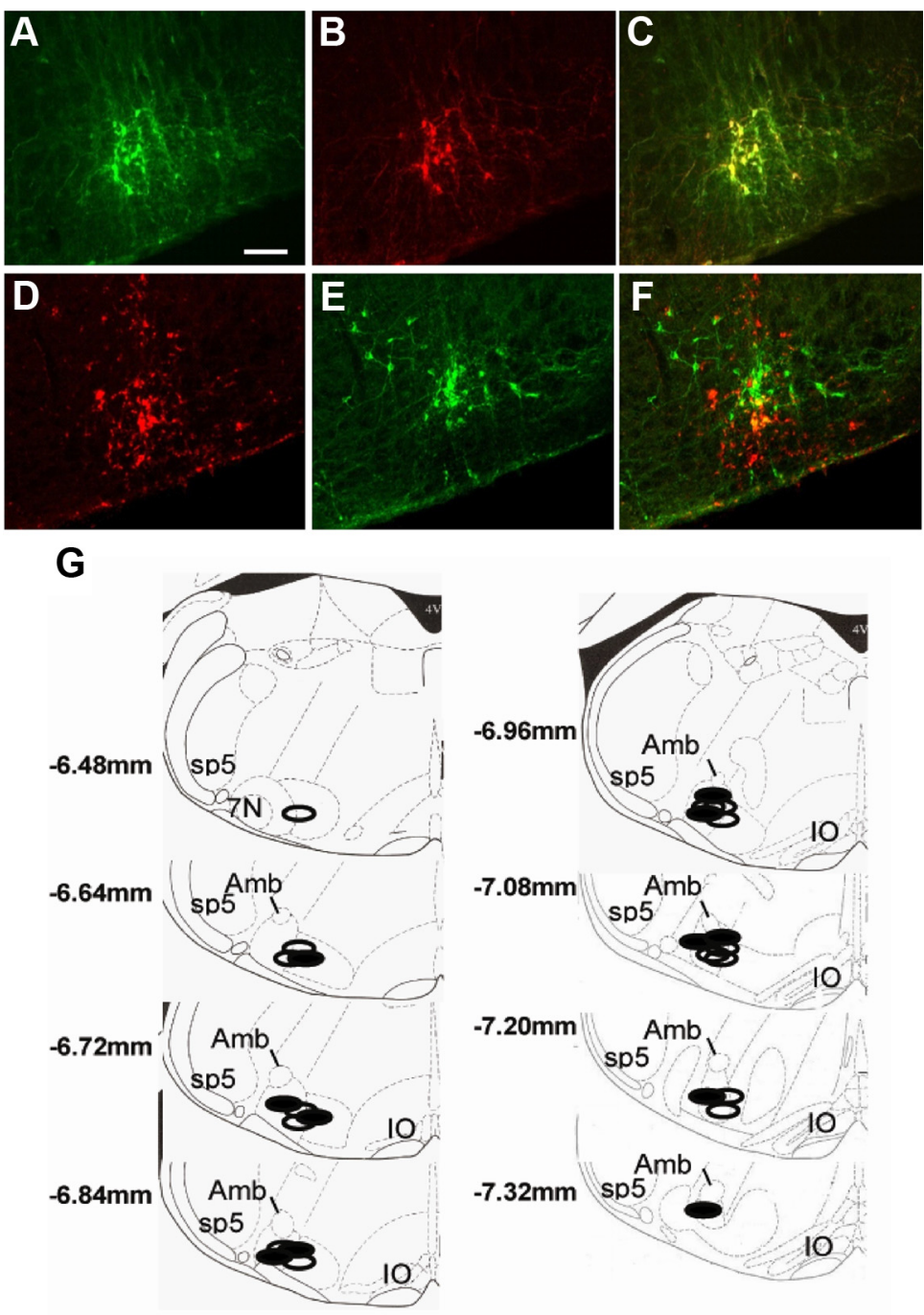

Figure 3. Photomicrographs of images obtained from fluorescence immunohistochemistry. $\boldsymbol{A}-\boldsymbol{C}$, The top row shows immunohistochemistry for GFP produced following microinjection of Lv-PRSx8-GFP in the RVLM $(\boldsymbol{A})$ with colocalization of TH $(\boldsymbol{B})$ on the . Correlation of the two markers indicates correct microinjection placement. Scale bar: $\boldsymbol{A}$ (for $\boldsymbol{A}-\boldsymbol{F}$ ), $100 \mu \mathrm{m} . \boldsymbol{G}$, Schematic range of all viral microinjections in the $A T_{1 A} R^{-/-}$mice included in this study. The open areas are RVLM Lv-PRSx8-GFP-injected $A T_{1 A} R^{-/-}$mice, and the blocked areas are RVLM Lv-PRSx8-AT ${ }_{1 A} R$-injected $A T_{1 A} R^{-/-}$mice. Some injections from different mice were in identical regions and are represented only by a single symbol. The numbers represent the distance from bregma. Amb, Nucleus ambiguus; 7N, facial motor nucleus; Sp5, spinal trigeminal tract; 10, inferior olivary nucleus.

as between Lv-PRSx8-AT ${ }_{1 \mathrm{~A}} \mathrm{R}$ and Lv-PRSx8-GFP at Day 33 (Table 1).

\section{Behavioral tests}

Cage-switch stress

Placing a male mouse in a cage occupied previously for 1 week by another male mouse is a strong aversive stressor that induces an increase in BP that is maintained for at least $90 \mathrm{~min}$. All mice showed similar initial pressor, tachycardic, and activity responses to the cage-switch stress (Fig. 6). Differences between cohorts were observed in the sustained phase of the response, which we measured as the average value over the entire $60 \mathrm{~min}$ cage-switch period. Lv-PRSx8-GFP mice showed a significant reduction in the sustained component of these responses, indicating that their $\mathrm{BP}$ and $\mathrm{HR}$ responses returned to baseline levels more quickly than the $A T_{1 A} R^{+/+}$mice (Fig. 6). Reexpression of the $\mathrm{AT}_{1 \mathrm{~A}} \mathrm{R}$ in 
A

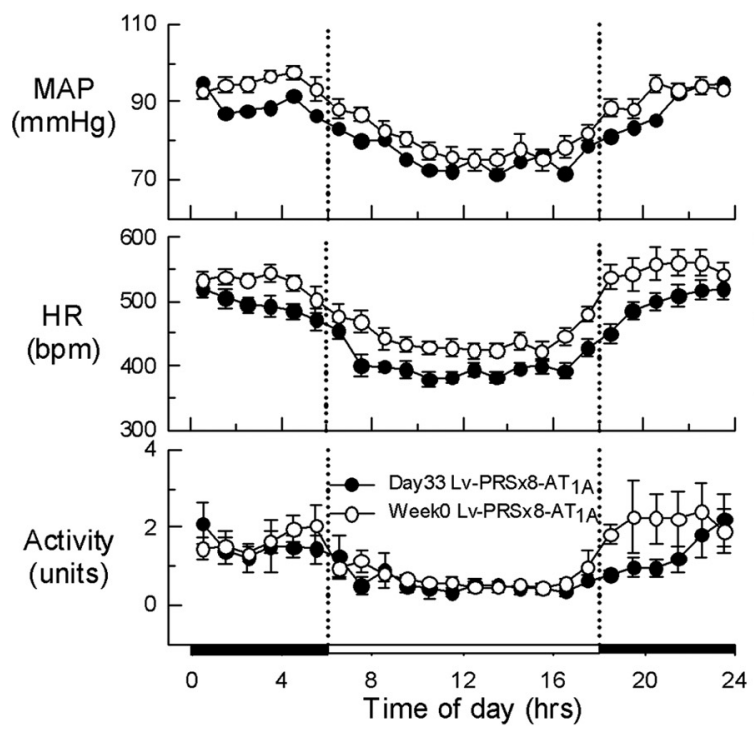

B

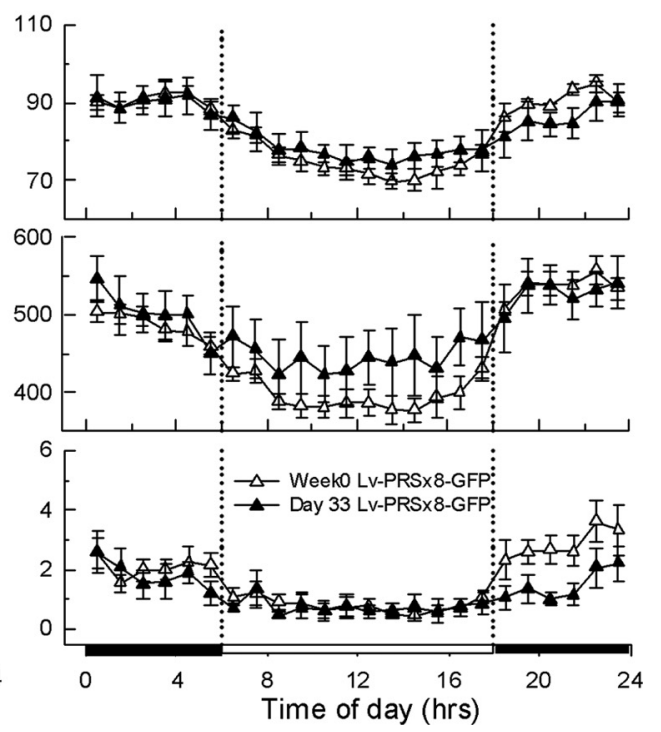

Figure 4. $\quad A, B$, Average hourly values for MAP, HR, and activity (arbitrary units) in $A T_{1 A} R^{-/-}$mice at Day 0 (open circles) and at Day 33 (closed circles) after RVLM microinjection of either (A) Lv-PRSx8-AT ${ }_{1 A} R(n=7)$ or (B) Lv-PRSx8-GFP $(n=5)$. The closed bar on the $x$-axis represents the dark period (active period), and the open bar represents the light period (inactive period). Error bars indicate SEM.

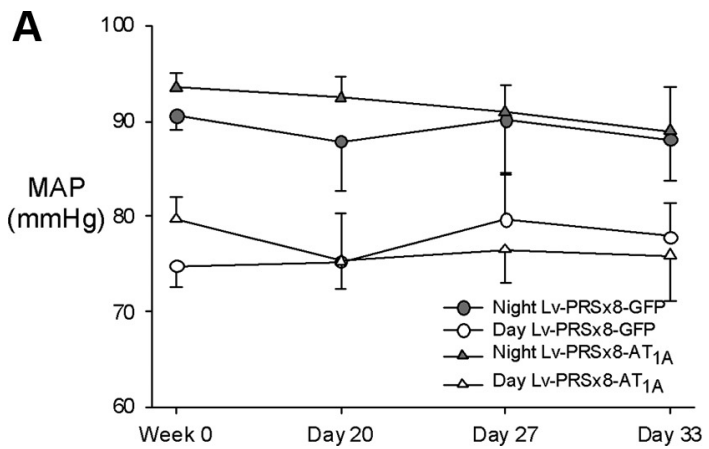

B

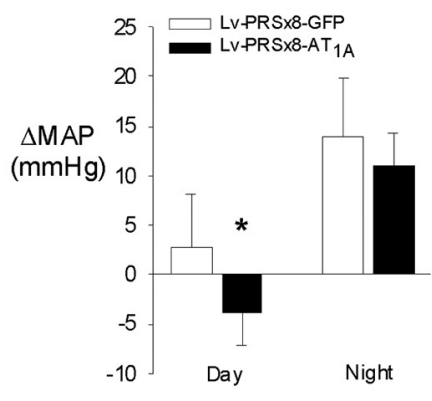

Figure 5. A, Grouped data for MAP during the day (6A.M. to 6P.M.) and night (6P.M. to 6 A.M.) periods at baseline (control) and 3 , 4, and 5 weeks following RVLM microinjection of either Lv-PRSX8-GFP $(n=5)$ or Lv-PRSX8-AT ${ }_{1 A} R(n=7)$. B, The bar graph shows the change in MAP observed when the values for Weeks 3,4 , and 5 are averaged and compared to baseline. Values are mean \pm SEM. ${ }^{*} p<0.05$.

C1 neurons induced a significantly greater sustained pressor response to the $1 \mathrm{~h}$ period of dirty-cage-switch stress compared to Lv-PRSx8-GFP mice (average change in MAP, $22 \pm 4 \mathrm{mmHg}$ vs $10 \pm 1 \mathrm{mmHg}$, respectively; $p<0.001$ ) (Fig. 6). While significantly increased relative to Lv-PRSx8-GFP, the sustained pressor response in $\mathrm{Lv}-\mathrm{PRS} \mathrm{x} 8-\mathrm{AT}_{1 \mathrm{~A}} \mathrm{R}$ mice remained reduced compared to the $A T_{1 A} R^{+/+}(28 \pm 2 \mathrm{mmHg} ; p<0.05)$. The cage-switchstress-induced HR $(155 \pm 12 \mathrm{bpm}$ vs $163 \pm 11 \mathrm{bpm}$, respectively) and locomotor responses were similar between Lv-PRSx8-AT ${ }_{1 \mathrm{~A}} \mathrm{R}$ and Lv-PRSx8-GFP groups and significantly reduced compared to $A T_{1 A} R^{+/+}$mice.

\section{Restraint stress}

Restraint stress was induced by placing mice in a tail cuff BP restrainer. No difference in the MAP or HR responses to this stress was observed between $A T_{1 A} R^{+/+}$mice and the Lv-PRSGFP group, but the Lv-PRSx8-AT ${ }_{1 \mathrm{~A}} \mathrm{R}$ group showed a significantly diminished pressor response and increased tachycardia $(p<0.001)$ (Fig. 7).

\section{Novel feeding stimulus}

The pressor response to presentation and eating of a novel, palatable food (almond) was increased in Lv-PRSx8-GFP compared to both $A T_{1 A} R^{+/+}$and Lv-PRSx8-AT ${ }_{1 \mathrm{~A}} \mathrm{R}$ mice (MAP, $27 \pm 1 \mathrm{mmHg}$ vs $25 \pm 3$ mmHg; HR, $198 \pm 15$ bpm vs $171 \pm 11$ bpm) (Fig. 7). The HR response was significantly elevated in the Lv-PRSx8-AT ${ }_{1 \mathrm{~A}} \mathrm{R}$ and Lv-PRSx8-GFP compared to $A T_{1 A} R^{+/+}$ mice (Fig. 7).

\section{Discussion}

Using several transgenic mouse models, we demonstrated that the $\mathrm{AT}_{1 \mathrm{~A}} \mathrm{R}$ is endogenously expressed in RVLM C1 neurons and required for the pressor response to microinjection of AngII into this nucleus. Lentiviral expression of this $\mathrm{AT}_{1 \mathrm{~A}} \mathrm{R}$ in the $\mathrm{C} 1$ neurons of adult $A T_{1 A} R^{-/-}$mice did not alter basal BP or HR but significantly increased the sustained pressor response to cage-switch stress toward that of $A T_{1 A} R^{+/+}$mice. Lentiviral expression of the $\mathrm{AT}_{1 \mathrm{~A}} \mathrm{R}$ in $\mathrm{C} 1$ neurons did not alter the HR or activity response to cage-switch stress. The effect of $\mathrm{AT}_{1 \mathrm{~A}} \mathrm{R}$ expression in $\mathrm{C} 1$ neurons on the immediate pressor response to cage-switch or restraint stressors or the appetitive stimulus was more variable. These observations argue that endogenous AngII acts on $\mathrm{C} 1$ neurons to modulate the $\mathrm{BP}$ response to aversive stress. In addition, our results clearly link activation of the RVLM C1 neurons to the sustained elevation of BP elicited by cageswitch stress.

Two lines of evidence support the conclusion that RVLM C1 neurons express $\mathrm{AT}_{1 \mathrm{~A}} \mathrm{R}$ endogenously. First, in a transgenic mouse with a bacterial artificial chromosome, in which the $\mathrm{AT}_{1 \mathrm{~A}} \mathrm{R}$ promoter drives expression of GFP, transgene expression occurs in rostral RVLM C1 neurons. These are presumptive sympathetic premotor neurons. Autoradiographic and in situ hybrid- 
Table 1. Average spectral power in low-, mid-, and high-frequency bands for MAP, HR, coherence, and gain in Lv-PRSx8-AT ${ }_{1 A}$ and Lv-PRSx8-GFP RVLM-microinjected mice assessed during the inactive period

\begin{tabular}{|c|c|c|c|c|c|c|c|c|}
\hline & $\begin{array}{l}\text { Week } 0 \\
\text { Lv-PRSx8-GFP }\end{array}$ & $\begin{array}{l}\text { Week } 0 \\
\text { Lv-PRSx8-AT }_{1 A} R\end{array}$ & $\begin{array}{l}\text { Day } 33 \\
\text { Lv-PRSx8-GFP }\end{array}$ & $\begin{array}{l}\text { Day } 33 \\
\text { Lv-PRSx8-AT }_{1 A} R\end{array}$ & $\begin{array}{l}\text { Week } 0 \\
\text { Lv-PRSx8-GFP vs } \\
\text { Lv-PRSx8-AT } 1{ }_{1 A} R\end{array}$ & $\begin{array}{l}\text { Day } 33 \\
\text { Lv-PRSx8-GFP vs } \\
\text { Lv-PRSx8-AT }_{1 A} R\end{array}$ & $\begin{array}{l}\text { Week } 0 \text { vs Day } 33 \\
\text { Lv-PRSx8-GFP }\end{array}$ & $\begin{array}{l}\text { Week } 0 \text { vs Day } 33 \\
\text { Lv-PRSx8-AT }_{1 A} R\end{array}$ \\
\hline \multicolumn{9}{|l|}{ Coherence } \\
\hline Midfrequency & $0.63 \pm 0.02$ & $0.60 \pm 0.01$ & $0.63 \pm 0.02$ & $0.63 \pm 0.02$ & ns & ns & ns & ns \\
\hline High frequency & $0.46 \pm 0.03$ & $0.44 \pm 0.02$ & $0.46 \pm 0.02$ & $0.47 \pm 0.04$ & ns & ns & ns & ns \\
\hline \multicolumn{9}{|l|}{ Gain (bpm/mmHg) } \\
\hline High frequency & $28.6 \pm 2.0$ & $24.3 \pm 2.0$ & $25.8 \pm 2.8$ & $19.8 \pm 0.9$ & ns & ns & ns & ns \\
\hline \multicolumn{9}{|l|}{$\operatorname{MAP}\left(\mathrm{mmHg}^{2}\right)$} \\
\hline Low frequency & $0.65 \pm 0.13$ & $0.66 \pm 0.16$ & $0.95 \pm 0.14$ & $0.58 \pm 0.07$ & ns & ns & ns & ns \\
\hline Midfrequency & $0.14 \pm 0.03$ & $0.23 \pm 0.09$ & $0.25 \pm 0.05$ & $0.12 \pm 0.01$ & ns & ns & ns & ns \\
\hline High frequency & $0.62 \pm 0.13$ & $0.63 \pm 0.09$ & $0.90 \pm 0.18$ & $0.59 \pm 0.08$ & ns & ns & ns & ns \\
\hline Total & $3.03 \pm 0.58$ & $2.82 \pm 0.46$ & $4.01 \pm 0.46$ & $2.39 \pm 0.24$ & ns & ns & ns & ns \\
\hline Total & $105 \pm 184$ & $1184 \pm 176$ & $1538 \pm 158$ & $926 \pm 126$ & ns & $*$ & ns & ns \\
\hline
\end{tabular}

Data are presented as mean $\pm \mathrm{SEM}$, indicating between-animal variance. Low frequency, $0.08-0.3 \mathrm{~Hz}$; midfrequency, $0.3-0.5 \mathrm{~Hz}$; high frequency, $0.5-1 \mathrm{~Hz}$; total, $0-1 \mathrm{~Hz}$. ns, Not significant. ${ }^{*} p<0.05$.

ization histochemical studies have demonstrated expression of $\mathrm{AT}_{1} \mathrm{R}$ in the RVLM of several species, including humans (Allen et al., 1988; Lenkei et al., 1997). These approaches did not provide the resolution or compatibility that enabled neurochemical characterization of the $\mathrm{AT}_{1} \mathrm{R}$-expressing cells. Immunohistochemical approaches have been difficult due to the low-level expression of the receptor and general issues surrounding specificity of antibodies directed to the $\mathrm{AT}_{1 \mathrm{~A}} \mathrm{R}$ (Smith et al., 1998). The transgenic mouse used in this study provides an alternative approach. Our observations concur with a previous immunohistochemical study (Wang et al., 2008) and support electrophysiological observations in slices of RVLM that demonstrate that AngII directly excites $\mathrm{C} 1$ neurons (Li and Guyenet, 1996). While transgenic mice represent a novel approach to examining the distribution of proteins for which standard approaches are problematic, there are methodological limitations due to potential ectopic expression. In this study, we mapped the distribution of GFP-expressing cells throughout the mouse CNS and compared it to the known distribution observed using in vitro autoradiography (Jenkins et al., 1997). The maps are very similar, although there were a few sites where, on the basis of autoradiography, we expected to see GFP but didn't. These tend to be regions of lower level expression, such as the area postrema and parabrachial nucleus. This may be due to reduced sensitivity or that the $\mathrm{AT}_{1 \mathrm{~B}} \mathrm{R}$ may be

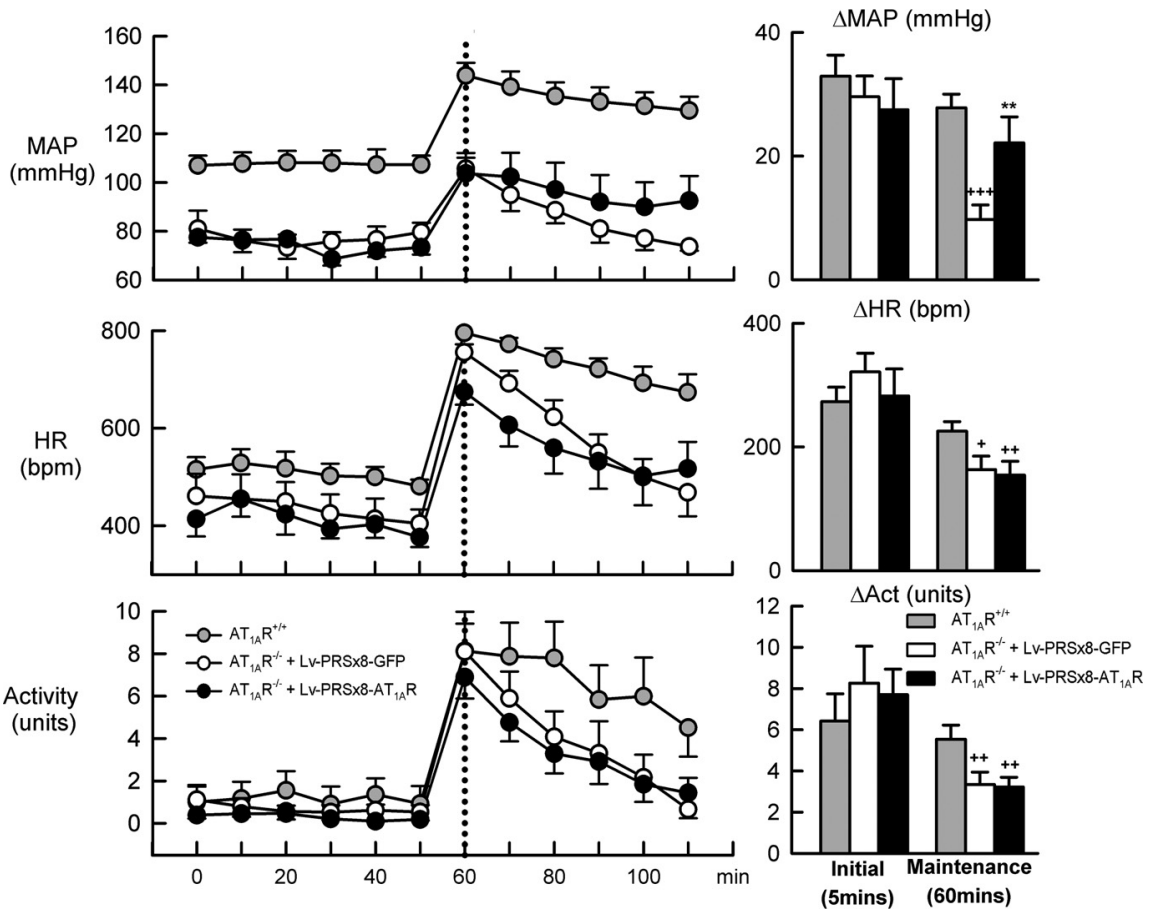

Figure 6. Effect of expression of $A T_{1 A}$ Rs in RVLM C1 neurons on the response to dirty-cage-switch stress. MAP and HR and activity (arbitrary units) were measured before and for $60 \mathrm{~min}$ after placing each male mouse in a cage occupied previously by another male mouse. Each point represents the mean \pm SEM of the average data for 10 min. Gray circles are $A T_{1 A} R^{+/+}$mice $(n=$ 6), open circles are $A T_{1 A} R^{-/-}$mice injected with $\operatorname{Lv}$-PRSX8-GFP $(n=5)$, and filled circles are $A T_{1 A} R^{-/-}$mice injected with $\mathrm{Lv}-\mathrm{PRS} \times 8-\mathrm{AT}_{1 \mathrm{~A}} \mathrm{R}(n=7)$. The same color scheme applies to the bar graphs, which show average changes in each parameter over with the initial 5 min period or the entire 60 min period compared to the control period. Plus signs denote comparison to the $A T_{1 A} R^{+/+}$mice, while asterisks denote comparison with Lv-PRSX8-GFP-injected mice. One symbol represents $p<0.05$, two symbols represent $p<0.01$, and three symbols represent $p<0.001$.

responsible for the majority of $\mathrm{AT}_{1} \mathrm{R}$ binding observed in some nuclei.

Second, we used lentiviruses with the PRSx8 promoter to drive Cre expression in the RVLM of mice containing a conditional $\mathrm{AT}_{1 \mathrm{~A}} \mathrm{R}$ allele. These mice, which showed no change in their 


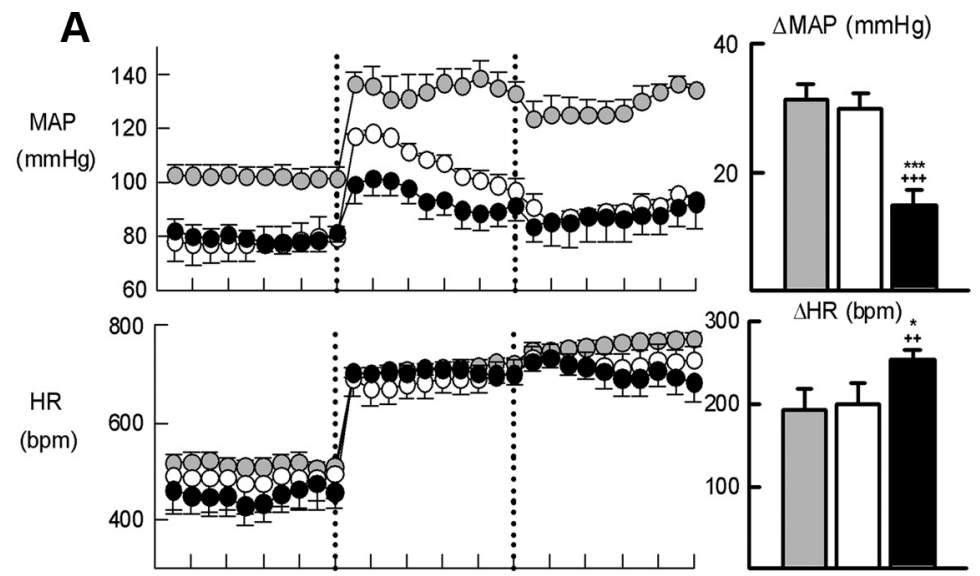

\section{B}

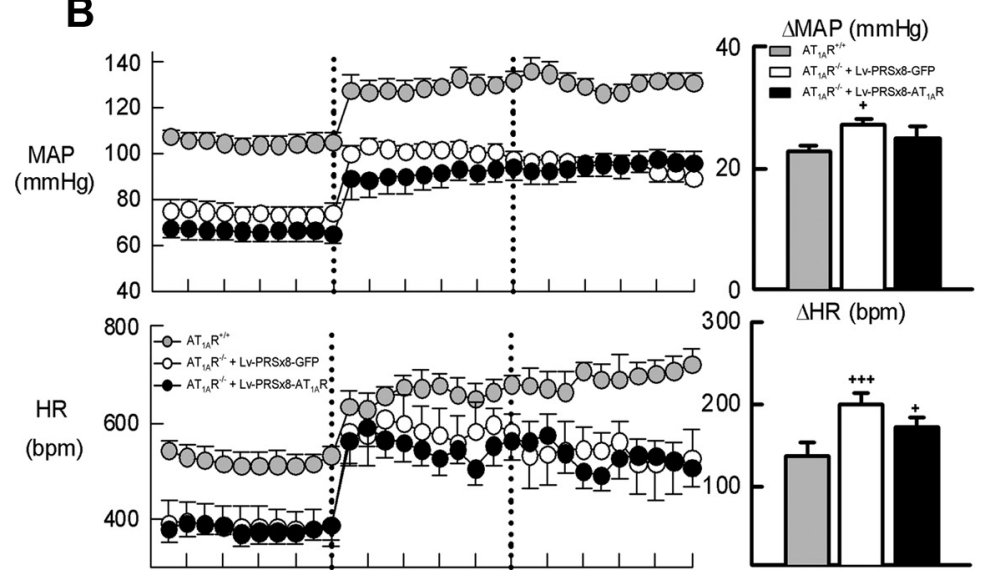

Figure 7. $\quad \boldsymbol{A}, \boldsymbol{B}$, Effect of expression of $A T_{1 A}$ Rs in RVLM 1 neurons on the short-term MAP and HR responses to restraint stress $(\boldsymbol{A})$ and novel food stimulus $(B)$ in $A T_{1 A} R^{+/+}$(gray symbols) and $A T_{1 A} R^{-/-}$mice microinjected in the RVLM with either Lv-PRSx8$\mathrm{AT}_{1 \mathrm{~A}} \mathrm{R}(n=7$; closed circles) or Lv-PRSx8-GFP ( $n=5$; open circles). Each symbol represents an average (mean \pm SEM) for each $30 \mathrm{~s}$ period. The bar graphs represent the average change in the measured parameters in each group. These average responses were calculated from a 5 min control period and 5 min of each stressor (the period between the dotted lines). Plus signs denotes comparison to the $A T_{1 A} R^{+/+}$mice, while asterisks denotes comparison with Lv-PRSX8-GFP-injected mice. One symbol represents $p<0.05$, two symbols represent $p<0.01$, and three symbols represet $p<0.001$.

response to RVLM microinjection of glutamate, did not show a pressor response to microinjection of AngII. The response to AngII was not affected by injection of Lv-PRSx8-GFP. Together, these data strongly support the conclusion that AngII acts in the RVLM to increase BP via the $\mathrm{AT}_{1 \mathrm{~A}} \mathrm{R}$ which is endogenously expressed on $\mathrm{C} 1$ neurons.

The pressor response induced by aversive stressors has two phases-an initial rapid phase reliant upon glutamatergic transmission in the RVLM and a sustained phase, which partially involves AngII action in the RVLM (Mayorov and Head, 2002, 2003). Blockade of RVLM AT ${ }_{1} \mathrm{R}$ attenuates the sustained cardiovascular response to aversive air-jet stress in conscious rabbits, without affecting the initial response (Mayorov and Head, 2003). Similarly, the sustained pressor response to aversive stress is diminished in $A T_{1 A} R^{-/-}$mice, with an associated decrease in Fos expression in RVLM neurons (Davern et al., 2009). In the current study, cage-switch stress in $A T_{1 A} R^{-/-}$mice expressing $\mathrm{AT}_{1 \mathrm{~A}} \mathrm{R}$ in $\mathrm{C} 1$ neurons induced a sustained elevation in BP compared to Lv-PRSx8-GFP-injected $A T_{1 A} R^{-/-}$mice. This mimics the BP response to cage-switch stress in wild-type mice (Davern et al., 2009). In contrast, the pressor response in the Lv-PRSx8-GFPinjected $A T_{1 A} R^{-1-}$ mice starts to return to baseline by $20 \mathrm{~min}$ and has reached baseline by the end of the cage-switch test. This ob- servation is consistent with that seen in the $A T_{1 A} R^{-/-}$mice (Davern et al., 2009). We conclude that the sustained pressor response to cage-switch stress is dependent upon AngII acting on the $\mathrm{AT}_{1 \mathrm{~A}} \mathrm{R}$ in $\mathrm{C} 1$ neurons. The outstanding question relates to the source of the AngII that provides this activation. Unfortunately our understanding of the biochemistry of the brain renin-angiotensin system and the localization of its components remains incomplete such that this question cannot be definitively answered.

The response of the lentiviral-injected $A T_{1 A} R^{-1-}$ mice to short-term stress is more variable, both within this study and in comparison to results from previous studies (Chen et al., 2009). In this study, the initial pressor response to aversive stress is either not altered (cage switch) or significantly reduced (restraint) in the Lv-PRSx8-AT ${ }_{1 \mathrm{~A}}$ R-expressing $\quad A T_{1 A} R^{-/-}$ mice, while the pressor response to an appetitive stimulus is slightly reduced relative to the GFP-expressing mice and not different from the $A T_{1 A} R^{+/+}$mice. In published observations (Chen et al., 2009), the $A T_{1 A} R^{-/-}$mice showed a diminished response to the appetitive and restraint stimuli compared to $A T_{1 A} R^{+/+}$ mice, which is not replicated here by the Lv-PRSx8-GFP-injected mice. It is possible that GFP expression has altered the response to restraint stress, but this is unlikely as none of the other observations related to the Lv-PRSx8-GFP mice show any substantial difference compared to $A T_{1 A} R^{-/-}$mice from previous studies. The reason for this discrepancy is not clear and suggests caution in relation to drawing strong conclusions about the responses to short-term stressors.

The link between acute aversive stress and cardiovascular events such as myocardial infarction is clearly established (Willich et al., 1993; Mittleman et al., 1995; Leor et al., 1996). There is also a growing recognition that chronic inescapable or unpredictable stress contributes to the development of essential hypertension in some people (Esler, 2009). The mechanisms underpinning this involvement in hypertension remain unclear. We propose that the sustained increase in BP induced by AngII in RVLM has significance for understanding how exposure to repeated aversive stressors could lead to hypertension. If BP remains elevated from one aversive stress exposure to the next, it is possible that a tetanic response could occur. This, combined with potential trophic effects of the elevated SNA (Hardebo, 1992; Mancia et al., 1999), could lead to sustained elevations of BP and consequent cardiovascular disease.

Cage-switch stress also induced tachycardia and increases in activity. Injection of Lv-PRSx8-AT ${ }_{1 \mathrm{~A}} \mathrm{R}$ in RVLM did not alter either of these parameters. This suggests that the tachycardia induced by cage-switch stress is produced by an alternative pathway activating cardiac sympathetic activity, or by withdrawal of cardiac vagal activity. Cage-switch stress in mice activates neurons in 
raphe pallidus (Davern et al., 2009), which is involved in the sympathetic HR response to some stressors (Zaretsky et al., 2003). While our studies do not provide further information about the pathways involved in the cardiac response to aversive stress, the lack of effect on this pathway adds considerable strength to the specificity of our observations on the role of $\mathrm{C} 1$ neurons.

Appetitive stimuli induce a distinct rise in $\mathrm{BP}$ and $\mathrm{HR}$ in both experimental animals and humans (Del Bo et al., 1985; Brosschot and Thayer, 2003; Braesicke et al., 2005). Feeding-associated arousal is initiated by the activation of descending inputs from the CNS rather than the viscerosympathetic reflex responses (Diamond and LeBlanc, 1987; Matsukawa and Ninomiya, 1987). In our study, presentation of a novel palatable food elicited a pressor and tachycardic response, with only minor differences between groups. In addition, the cardiovascular responses to the appetitive stimulus are comparable to those seen in the naive $A T_{1 A} R^{-/-}$ and $A T_{1 A} R^{+/+}$mice (Chen et al., 2009). The lack of BP difference in the appetitive stimulus suggests that either the RVLM C1 neurons or AngII is not essential to this response.

We had hypothesized that expression of $\mathrm{AT}_{1 \mathrm{~A}} \mathrm{R}$ in $\mathrm{C} 1$ neurons might increase resting $\mathrm{BP}$ in the $A T_{1 A} R^{-/-}$mice. However, the observed lack of effect, and potentially a small decrease in daytime resting $\mathrm{BP}$, is supported by previous observations. Little or no $\mathrm{BP}$ change occurs in response to microinjection of $\mathrm{AT}_{1} \mathrm{R}$ antagonists into the RVLM of normotensive animals under basal conditions (Allen et al., 2009). Transgenic mice with neuronal overexpression of the $\mathrm{AT}_{1 \mathrm{~A}} \mathrm{R}$ have normal resting $\mathrm{BP}$, despite having exaggerated pressor responses to intracerebroventricular infusion of AngII (Lazartigues et al., 2002). Thus, it seems that under basal conditions AngII has little effect on RVLM neurons to regulate BP. In contrast, under conditions where the AngII input to RVLM is activated, either by physiological stimuli or in pathological states such as hypertension, $\mathrm{AT}_{1} \mathrm{R}$ antagonists produce significant decreases in BP through inhibition of sympathetic efferent activity (Allen et al., 2009). This supports the observation that activation of the receptor, and not just increased expression, is required for an altered phenotype.

In this study, we demonstrate that the $\mathrm{AT}_{1 \mathrm{~A}} \mathrm{R}$ is expressed in $\mathrm{C} 1$ neurons and required for the pressor response to AngII in this nucleus. Furthermore, transgenic expression of the $\mathrm{AT}_{1 \mathrm{~A}} \mathrm{R}$ in $\mathrm{C} 1$ neurons in adult $A T_{1 A} R^{-/-}$mice modulates the pressor response to cage-switch stress, implicating both these cells and this receptor system in the stress pathway. Of importance is the demonstration that expression of the $\mathrm{AT}_{1 \mathrm{~A}} \mathrm{R}$ in $\mathrm{C} 1$ neurons returns the $\mathrm{BP}$ response to cage-switch stress toward that of the $A T_{1 A} R^{+/+}$ mouse. This implies that AngII is released within the RVLM in response to cage-switch stress and serves to sustain the pressor response. We propose that this sustained activation of autonomic activity could underpin the development of hypertension induced by repeated aversive stressors.

\section{References}

Abbott SB, Stornetta RL, Socolovsky CS, West GH, Guyenet PG (2009) Photostimulation of channelrhodopsin-2 expressing ventrolateral medullary neurons increases sympathetic nerve activity and blood pressure in rats. J Physiol 587:5613-5631.

Aguilera G, Kiss A, Luo X, Akbasak BS (1995) The renin angiotensin system and the stress response. Ann N Y Acad Sci 771:173-186.

Allen AM, Chai SY, Clevers J, McKinley MJ, Paxinos G, Mendelsohn FA (1988) Localization and characterization of angiotensin II receptor binding and angiotensin converting enzyme in the human medulla oblongata. J Comp Neurol 269:249-264.

Allen AM, Moeller I, Jenkins TA, Zhuo J, Aldred GP, Chai SY, Mendelsohn FA
(1998) Angiotensin receptors in the nervous system. Brain Res Bull 47:17-28.

Allen AM, O'Callaghan EL, Chen D, Bassi JK (2009) Central neural regulation of cardiovascular function by angiotensin: a focus on the rostral ventrolateral medulla. Neuroendocrinology 89:361-369.

Armando I, Carranza A, Nishimura Y, Hoe KL, Barontini M, Terron JA, Falcon-Neri A, Ito T, Juorio AV, Saavedra JM (2001) Peripheral administration of an angiotensin II AT(1) receptor antagonist decreases the hypothalamic-pituitary-adrenal response to isolation stress. Endocrinology 142:3880-3889.

Baudrie V, Laude D, Elghozi JL (2007) Optimal frequency ranges for extracting information on cardiovascular autonomic control from the blood pressure and pulse interval spectograms in mice. Am J Physiol 292:R904-R912.

Braesicke K, Parkinson JA, Reekie Y, Man MS, Hopewell L, Pears A, Crofts H, Schnell CR, Roberts AC (2005) Autonomic arousal in an appetitive context in primates: a behavioural and neural analysis. Eur J Neurosci 21:1733-1740.

Brosschot JF, Thayer JF (2003) Heart rate response is longer after negative emotions than after positive emotions. Int J Psychophysiol 50:181-187.

Butz GM, Davisson RL (2001) Long-term telemetric measurement of cardiovascular parameters in awake mice: a physiological genomics tool. Physiol Genomics 5:89-97.

Card JP, Sved JC, Craig B, Raizada M, Vazquez J, Sved AF (2006) Efferent projections of rat rostroventrolateral medulla $\mathrm{C} 1$ catecholamine neurons: implications for the central control of cardiovascular regulation. J Comp Neurol 499:840-859.

Chen D, La Greca L, Head GA, Walther T, Mayorov DN (2009) Blood pressure reactivity to emotional stress is reduced in AT1A-receptor knockout mice on normal, but not high salt intake. Hypertens Res 32:559-564.

Chen D, Bassi JK, Walther T, Thomas WG, Allen AM (2010) Expression of angiotensin type $1 \mathrm{~A}$ receptors in $\mathrm{C} 1$ neurons restores the sympathoexcitation to angiotensin in the rostral ventrolateral medulla of angiotensin type 1A knockout mice. Hypertension 56:143-150.

Dampney RA (1994) Functional organization of central pathways regulating the cardiovascular system. Physiol Rev 74:323-364.

Davern PJ, Chen D, Head GA, Chavez CA, Walther T, Mayorov DN (2009) Role of angiotensin II type $1 \mathrm{~A}$ receptors in cardiovascular reactivity and neuronal activation after aversive stress in mice. Hypertension 54:1262-1268.

Del Bo A, Le Doux JE, Reis DJ (1985) Sympathetic nervous system and control of blood pressure during natural behaviour. J Hypertens 3:S105-S106.

De Matteo R, Head GA, Mayorov DN (2006) Angiotensin II in dorsomedial hypothalamus modulates cardiovascular arousal caused by stress but not feeding in rabbits. Am J Physiol 290:R257-R264.

Diamond P, LeBlanc J (1987) Hormonal control of postprandial thermogenesis in dogs. Am J Physiol 253:E521-E529.

Esler M (2009) Heart and mind: psychogenic cardiovascular disease. J Hypertens 27:692-695.

Gembardt F, Heringer-Walther S, van Esch JH, Sterner-Kock A, van Veghel R, Le TH, Garrelds IM, Coffman TM, Danser AH, Schultheiss HP, Walther T (2008) Cardiovascular phenotype of mice lacking all three subtypes of angiotensin II receptors. FASEB J 22:3068-3077.

Gurley SB, Riquier-Brison AD, Schnermann J, Sparks MA, Allen AM, Haase VH, Snouwaert JN, Le TH, McDonough AA, Koller BH, Coffman TM (2011) AT1A angiotensin receptors in the renal proximal tubule regulate blood pressure. Cell Metabolism 13:469-475.

Hardebo JE (1992) Influence of impulse pattern on noradrenaline release from sympathetic nerves in cerebral and some peripheral vessels. Acta Physiol Scand 144:333-339.

Head GA, Lukoshkova EV, Burke SL, Malpas SC, Lambert EA, Janssen BJ (2001) Comparing spectral and invasive estimates of baroreflex gain. IEEE Trans Biomed Eng 20:43-52.

Head GA, Obeyesekere VR, Jones ME, Simpson ER, Krozowski ZS (2004) Aromatase-deficient (ArKO) mice have reduced blood pressure and baroreflex sensitivity. Endocrinology 145:4286-4291.

Jackson K, Head GA, Morris BJ, Chin-Dusting J, Jones E, La Greca L, Mayorov DN (2007) Reduced cardiovascular reactivity to stress but not feeding in renin enhancer knockout mice. Am J Hypertens 20:893-899.

Janssen BJ, Smits JF (2002) Autonomic control of blood pressure in mice: 
basic physiology and effects of genetic modification. Am J Physiol 282:R1545-R1564.

Jenkins TA, Chai SY, Mendelsohn FAO (1997) Upregulation of angiotensin II AT $\mathrm{T}_{1}$ receptors in the mouse nucleus accumbens by chronic haloperidol treatment. Brain Res 748:137-142.

Kahan T, Eliasson K (1999) The influence of long-term ACE inhibitor treatment on circulatory responses to stress in human hypertension. Am J Hypertens 12:1188-1194.

Lazartigues E, Dunlay SM, Loihl AK, Sinnayah P, Lang JA, Espelund JJ, Sigmund CD, Davisson RL (2002) Brain-selective overexpression of angiotensin (AT1) receptors causes enhanced cardiovascular sensitivity in transgenic mice. Circ Res 90:617-624.

Lee DL, Webb RC, Brands MW (2004) Sympathetic and angiotensindependent hypertension during cage-switch stress in mice. Am J Physiol 287:R1394-R1398.

Lenkei Z, Palkovits M, Corvol P, Llorens-Cortes C (1997) Expression of angiotensin type-1 (AT1) and type-2 (AT2) receptor mRNAs in the adult rat brain: a functional neuroanatomical review. Front Neuroendocrinol 18:383-439.

Leor J, Poole WK, Kloner RA (1996) Sudden cardiac death triggered by an earthquake. N Engl J Med 334:413-419.

Li YW, Guyenet PG (1996) Angiotensin II decreases a resting K+ conductance in rat bulbospinal neurons of the $\mathrm{C} 1$ area. Circ Res 78:274-282.

Lipski J, Kanjhan R, Kruszewska B, Smith M (1995) Barosensitive neurons in the rostral ventrolateral medulla of the rat in vivo: morphological properties and relationship to C1 adrenergic neurons. Neuroscience 69:601-618.

Llewellyn-Smith IJ, Martin CL, Marcus JN, Yanigasawa M, Minson JB, Scammell TE (2003) Orexin-immunoreactive inputs to rat sympathetic preganglionic neurons. Neurosci Lett 351:115-119.

Mancia G, Grassi G, Giannattasio C, Seravalle G (1999) Sympathetic activation in the pathogenesis of hypertension and progression of organ damage. Hypertension 34:724-728.

Matsukawa K, Ninomiya I (1987) Changes in renal sympathetic nerve activity, heart rate and arterial blood pressure associated with eating in cats. J Physiol 390:229-242.

Mayorov DN, Head GA (2002) Ionotropic glutamate receptors in the rostral ventrolateral medulla mediate sympathetic responses to acute stress in conscious rabbits. Auton Neurosci 98:20-23.

Mayorov DN, Head GA (2003) AT1 receptors in the RVLM mediate pressor responses to emotional stress in rabbits. Hypertension 41:1168-1173.
Mittleman MA, Maclure M, Sherwood JB, Mulry RP, Tofler GH, Jacobs SC, Friedman R, Benson H, Muller JE (1995) Triggering of acute myocardial infarction onset by episodes of anger. Determinants of Myocardial Infarction Onset Study Investigators. Circulation 92:1720-1725.

Navakatikyan MA, Barrett CJ, Head GA, Ricketts JH, Malpas SC (2002) A real-time algorithm for the quantification of blood pressure waveforms. IEEE Trans Biomed Eng 49:662-670.

Paxinos G, Franklin KBJ (2004) The mouse brain in stereotaxic coordinates, Ed 2. San Diego: Elsevier Science.

Phillips JK, Goodchild AK, Dubey R, Sesiashvili E, Takeda M, Chalmers J, Pilowsky PM, Lipski J (2001) Differential expression of catecholamine biosynthetic enzymes in the rat ventrolateral medulla. J Comp Neurol 432:20-34.

Saavedra JM, Benicky J (2007) Brain and peripheral angiotensin II play a major role in stress. Stress 10:185-193.

Schreihofer AM, Guyenet PG (1997) Identification of C1 presympathetic neurons in rat rostral ventrolateral medulla by juxtacellular labeling in vivo. J Comp Neurol 387:524-536.

Smith RD, Baukal AJ, Zolyomi A, Gaborik Z, Hunyady L, Sun L, Zhang M, Chen HC, Catt KJ (1998) Agonist-induced phosphorylation of the endogenous AT1 angiotensin receptor in bovine adrenal glomerulosa cells. Mol Endocrinol 12:634-644.

Srinivas S, Watanabe T, Lin CS, William CM, Tanabe Y, Jessell TM, Costantini $F$ (2001) Cre reporter strains produced by targeted insertion of EYFP and ECFP into the ROSA26 locus. BMC Dev Biol 1:4.

Ulrich-Lai YM, Herman JP (2009) Neural regulation of endocrine and autonomic stress responses. Nat Rev Neurosci 10:397-409.

Vianna DM, Carrive P (2010) Cardiovascular and behavioural responses to conditioned fear and restraint are not affected by retrograde lesions of A5 and C1 bulbospinal neurons. Neuroscience 166:1210-1218.

Wang G, Milner TA, Speth RC, Gore AC, Wu D, Iadecola C, Pierce JP (2008) Sex differences in angiotensin signaling in bulbospinal neurons in the rat rostral ventrolateral medulla. Am J Physiol 295:R1149-R1157.

Willich SN, Maclure M, Mittleman M, Arntz HR, Muller JE (1993) Sudden cardiac death. Support for a role of triggering in causation. Circulation 87:1442-1450.

Zaretsky DV, Zaretskaia MV, Samuels BC, Cluxton LK, DiMicco JA (2003) Microinjection of muscimol into raphe pallidus suppresses tachycardia associated with air stress in conscious rats. J Physiol 546:243-250. 